\title{
ADHESION MEASUREMENTS OF METALLIZATIONS FOR HYBRID MICROCIRCUITS
}

\author{
H. G. KADEREIT and A. SCHLEMM
}

Siemens AG, Munich, West Germany

(Received June 3, 1977)

\begin{abstract}
In a method developed for measuring the adhesion of metallic films for hybrid microelectronic circuits, pull rods soldered or epoxy bonded to metallization pads are pulled off at an angle normal to the substrate. The test circuits and testing devices are described. Tensile strengths of 40 to $80 \mathrm{~N} / \mathrm{mm}^{2}$ and 5 to $30 \mathrm{~N} / \mathrm{mm}^{2}$ are typical for thin-film circuits and thick-film circuits, respectively. The weakest point in the overall circuit configuration is determined. The information obtained indicates the maximum permissible mechanical loads to which the discrete devices of microelectronic circuits can be exposed and may also be evaluated for process optimization.
\end{abstract}

\section{INTRODUCTION}

The adhesion of metal films deposited on glass and ceramic substrates is a significant figure of merit for the reliability of hybrid thin-film and thick-film circuits. It is dependent on the choice of substrate material, the film composition and the process by which the films are deposited. It can be further influenced by the material composition and the method by which discrete devices are bonded, as well as by the effects of aging and elevated temperatures during operation.

There are various methods of testing the adhesion of films, ${ }^{1-4}$ some of which however yield only qualitative data. The essential problem of testing the adhesion of films is that it is not usually possible to take hold of the film directly in order to peel it off normal to the plane of the substrate. Instead it is necessary to prepare samples for testing in a testing setup for the determination of their resistance to pull forces or peel forces, ${ }^{5}$ which is a measure of the adhesion of the metallization.

A method used by Siemens over some years for the quantitative testing of tensile strength in both process development and quality control will be outlined below and typical results of the testing of thinfilm and thick-film circuits reported.

\section{EXPERIMENTS}

A test sample with $1 \mathrm{~mm}$ by $1 \mathrm{~mm}$ pads to which copper pull rods $0.8 \mathrm{~mm}$ in diameter can be soldered or epoxy bonded normal to the plane of the film was used for testing. A schematic representation of the cross section through a soldered joint is shown in Figure 1. The adhesion reliability of the metallization is liable to be influenced by the attachment of the pull rods. This however simulates realistic conditions, as the adhesion of metallization at points where discrete devices have been bonded is of particular interest because it is precisely at such points that maximum stresses occur.

One of the principal advantages of this method is that normal hybridization practices can be simulated. Thus the pull rods can be attached with various solders or conductive and nonconductive epoxies under the conditions specified for hybridization processes. It is further possible to

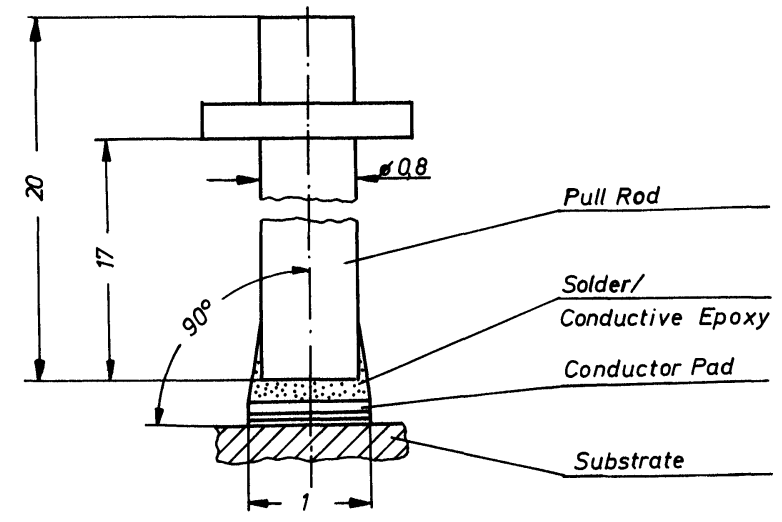

FIGURE 1 Soldered pull rod. 


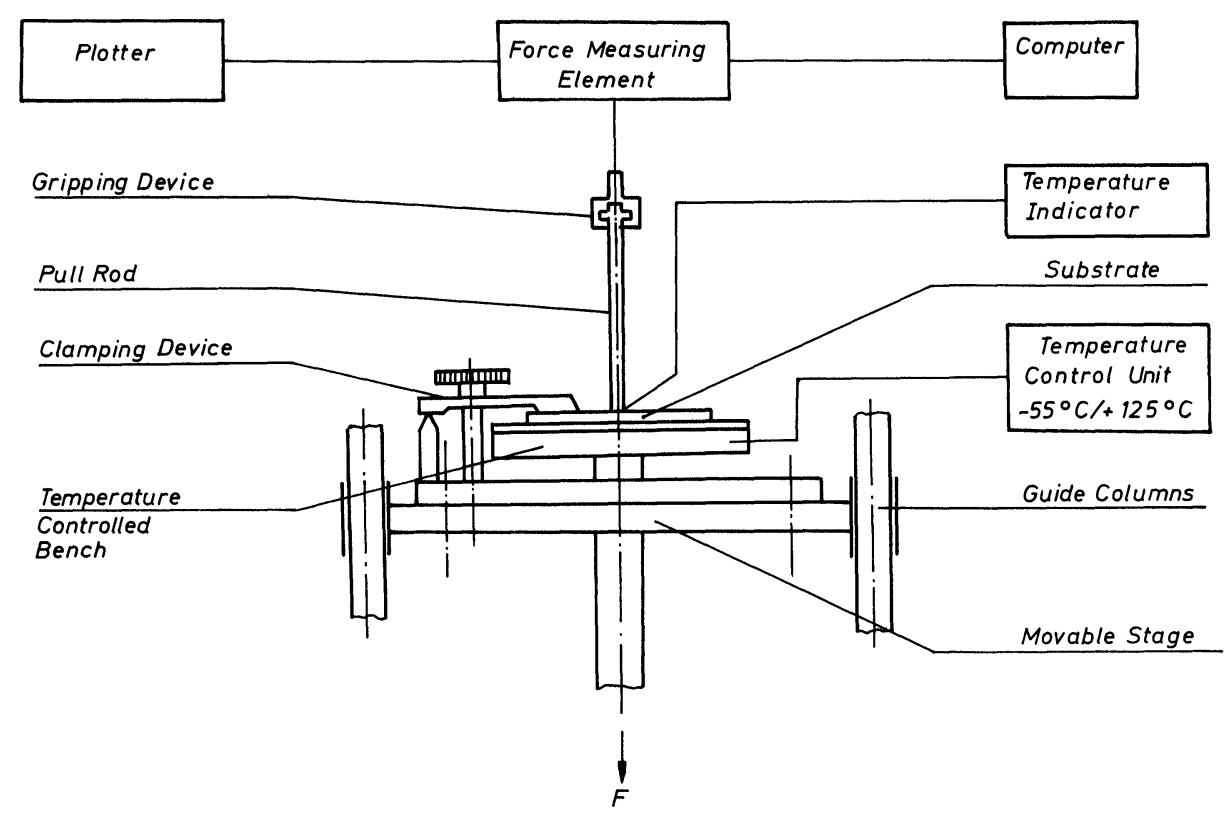

FIGURE 2 Schematic representation of test setup.

observe the effects of metallurgical changes from the aging of samples and to draw inferences concerning long-term performance and reliability.

The samples are clamped in the test setup shown schematically in Figure 2. A special gripping device grasps the pull rod and pulls at it with a rate of $10 \mathrm{~mm} / \mathrm{min}$. The resulting force measurements are communicated by the force measuring element of the pull machine to a plotter or, via an analog-todigital converter, to a computer. The tensile strength can be determined at various temperatures from a temperature-controlled bench. ${ }^{6}$

The tensile strength $\sigma_{Z}$ can be defined as the pull force $F$ divided by the surface area $A$ of the pad, expressed in $\mathrm{N} / \mathrm{mm}^{2}$

$$
\sigma_{Z}=F / A \text {. }
$$

Measurements performed on $4 \mathrm{~mm}^{2}$ pads for the purpose of comparison show that the above value can be expected for all bonds of conventional size encountered in practice. ${ }^{6}$

\section{RESULTS OF INVESTIGA'TION}

The tensile strength of various metallizations bonded with various solders and conductive epoxies was tested within the context of process development and quality control. Table I lists typical values recorded for the tensile strength.
For thin-film circuits on ceramic substrates tensile strengths better than $50 \mathrm{~N} / \mathrm{mm}^{2}$ are typical where conventional eutectic soft solders such as $\mathrm{Sn} 62 \mathrm{~Pb} 36$ $\mathrm{Ag} 2$ are used (1) and (3), while with glass substrates the values are somewhat lower (7). For high-temperature and low-temperature solders as used in stepwise soldering the adhesion reliability is usually lower. The adhesion reliability of Au80 Sn20 solder (2) (melting point $280^{\circ} \mathrm{C}$ ) is degraded by internal stresses, while that of $\mathrm{Pb} 90 \mathrm{Sn} 10$ (4) (melting point $310^{\circ} \mathrm{C}$ ) and $\mathrm{Pb} 25 \operatorname{In} 75(5)$ (melting point $165^{\circ} \mathrm{C}$ ) solders is limited by the softness of the solder. Satisfactory tensile strengths can be obtained by bonding discrete devices to thin-film circuits with conductive epoxy (6).

The tensile strength of thick-film circuits bonded with $\mathrm{Sn} 60 \mathrm{~Pb} 40$ or a similar solder with $\mathrm{Ag}$ is usually inferior to that of thin-film circuits, whereby the values for PdAu pastes (9) are below those of $\mathrm{PdAg}$ pastes (8). Table I lists for comparison the relevant data for copper-clad epoxide circuit boards reinforced with fiberglass (10) and Teflon circuit boards reinforced with fiberglass (11).

All the tabulated data were recorded directly after pull rods had been bonded to the samples. Solder and epoxy resin bonds are however subject to aging effects in the same way as metallization. In the interest of adhesion reliability it is therefore additionally necessary to determine the tensile strength after aging processes such as storage at 
TABLE I

Tensile strengths (survey)

\begin{tabular}{|c|c|c|c|c|}
\hline No. & Substrate & Technology & $\begin{array}{l}\text { Solderl } \\
\text { Conductive Epoxy }\end{array}$ & $\begin{array}{c}\text { Tensile Strength } \\
\mathrm{N} / \mathrm{mm} 2\end{array}$ \\
\hline 9 & \multirow{6}{*}{ Alumina $99,5 \%$} & \multirow{2}{*}{$\begin{array}{l}\text { Thin-film technology with electro- } \\
\text { plated Cu-layers for microwave } \\
\text { integrated circuits }\end{array}$} & $\operatorname{Sn} 62 \mathrm{~Pb} 36 \mathrm{Ag} 2$ & $60 \ldots 100$ \\
\hline 2 & & & Au $80 \operatorname{Sn} 20$ & $40 \ldots 50$ \\
\hline 3 & & \multirow{3}{*}{$\begin{array}{l}\text { Standard thin- } \\
\text { film technology } \\
\text { with integrated } \\
\text { NiCr-resistors }\end{array}$} & $\operatorname{Sn} 62 \mathrm{~Pb} 36 \mathrm{Ag} 2$ & $50 \ldots 70$ \\
\hline 4 & & & Pb90Sn 10 & $25 \ldots 45$ \\
\hline 5 & & & Pb $25 \operatorname{In} 75$ & $15 \ldots 20$ \\
\hline 6 & & $\begin{array}{l}\text { and electroplated } \\
\text { Au-layers }\end{array}$ & Ablebond $36-2^{*}$ & $40 \ldots 50$ \\
\hline 7 & $\begin{array}{c}\text { Corning-glass } \\
7059\end{array}$ & $\begin{array}{l}\text { Thin-film technology with integrated } \\
\text { NiCr-resistors }\end{array}$ & $\mathrm{Sn} 62 \mathrm{~Pb} 36 \mathrm{Ag} 2$ & $30 \ldots 50$ \\
\hline 8 & \multirow{2}{*}{ Alumina $92 \%$} & Thick-film technology,PdAg-pastes & \multirow{4}{*}{ Sn 60Pb40 } & $15 \ldots 30$ \\
\hline 9 & & Thick-film technology,PdAu-pastes & & $5 \ldots 20$ \\
\hline 10 & $\begin{array}{l}\text { Glass fibre rein- } \\
\text { forced epoxy }\end{array}$ & \multirow[t]{2}{*}{ Copper clad } & & $40 \ldots 50$ \\
\hline 11 & $\begin{array}{l}\text { Glass fibre rein- } \\
\text { forced teflon }\end{array}$ & & & $15 \ldots 20$ \\
\hline
\end{tabular}

Conductive Epoxy, Ablestik Laboratories, Cal.,USA

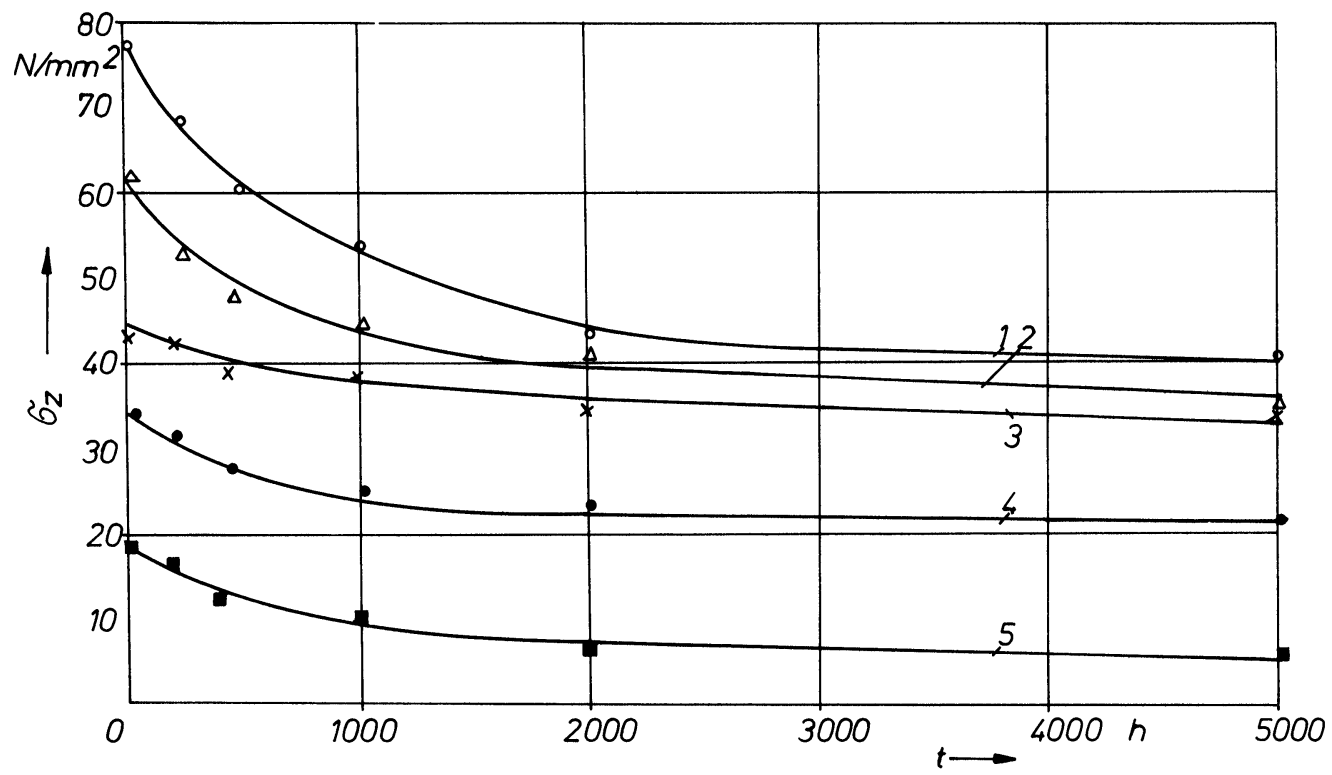

FIGURE 3 Tensile strength $\sigma_{z}$ vs. time $t$ during storage at $150^{\circ} \mathrm{C}$.

(1) Thin-film technology with electroplated Cu-layers/Sn62Pb36Ag2

(2) Standard thin-film technology/Sn6Pb36 Ag2

(3) Standard thin-film technology/Au80Sn20

(4) Standard thin-film technology/Pb90Sn10

(5) Thick-film technology with $\mathrm{PdAu}$ paste/Sn60 Pb40 


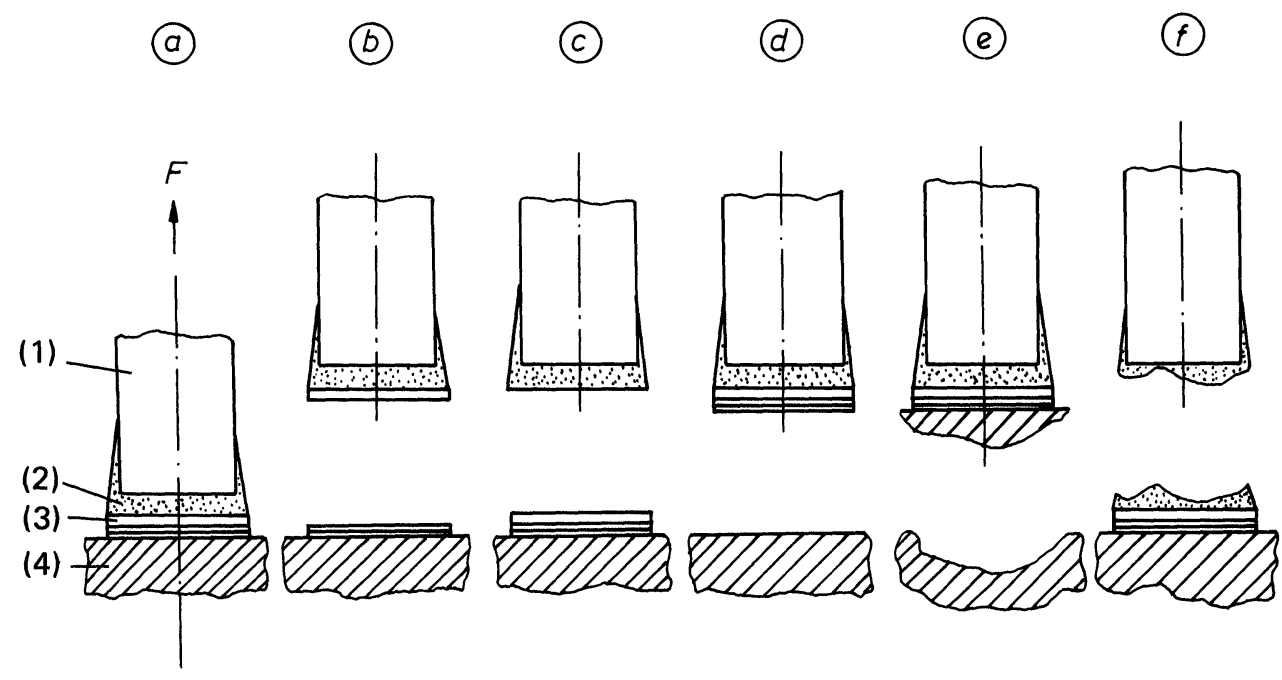

FIGURE 4 Typical ruptures.

$\begin{array}{llll}\text { (1) Pull rod (2) Solder/Conductive Epoxy (3) Film (4) Substrate } & \end{array}$

various temperatures or exposure to temperature cycling. Figure 3 shows as an example the variation of tensile strength as a function of time for various samples stored at $150^{\circ} \mathrm{C}$ for accelerated aging. All samples show a degradation of adhesion reliability, whereby the larger percentual degradation in the case of thin-film circuits with electroplated copper conductors is due to the formation of a brittle CuSn phase.

Since the tensile strength is determined on the basis of the weakest point of the sample, an investigation of the point of rupture needs to be included in the analysis of the results. Only if the location and type of rupture are known will it be possible to introduce measures for increasing adhesion reliability and to formulate an acceptable definition of the term tensile strength.

If the rupture occurs in the film (Figure 4b), at the surface of the film (Figure 4c), in the substrate (Figure 4e) or in the solder (Figure 4f) the measured pull force will represent a minimum for the adhesion reliability of films deposited to the substrate. Only if the rupture occurs at the substrate surface (Figure 4d) will the measured pull force equal the adhesion strength. Ruptures of this type are typical of thickfilm circuits made with $\mathrm{PdAu}$ pastes. For soldered thin-film circuits the rupture will usually occur in the substrate or in the solder itself. Ruptures between film and solder are often evidence of inadequate wetting or alloying of the solder.

\section{CONCLUSIONS}

The described method offers the advantage that tensile strenghts can be quantitatively determined with good reproducibility, so allowing the intercomparison of various technologies. Since the pull rods can be attached in the same way as discrete devices, various solders and conductive epoxies can be tested and the effect of specific process steps, such as repeated soldering in the case of repairs, on tensile strength determined. The determination of the weakest point of the sample is of particular significance in process optimization, while in quality control it may point to possible manufacturing defects. The tensile strength at the weakest point is also of critical interest to users, who may use it as a parameter for deriving guideline values for the mechanical properties of discrete devices bonded to thin-film and thick-film circuits.

\section{REFERENCES}

1. D. S. Campbell, in L. I. Maissel and G. Glang (eds), Handbook of Thin Film Technology, (M@Graw-Hill, New York, 1970).

2. R. Jacobsson, Thin Solid Films, 34, (1976), 101-199.

3. S. S. Leven, Proc. 26th Electr. Comp. Conf., (1976), 285-291.

4. E. R. Naimon, D. Vigil, J. P. Villegas and L. Williams, J. Vac. Sci. Technol., 13, (1976), 1131-1134.

5. T. G. Reissing, Radio Mentor Electronic, 39, (1973), 558.

6. H. G. Kadereit, A. Schlemm, Siemens Forschungs- und Entwicklungsberichte, 6, (1977), 220-225. 

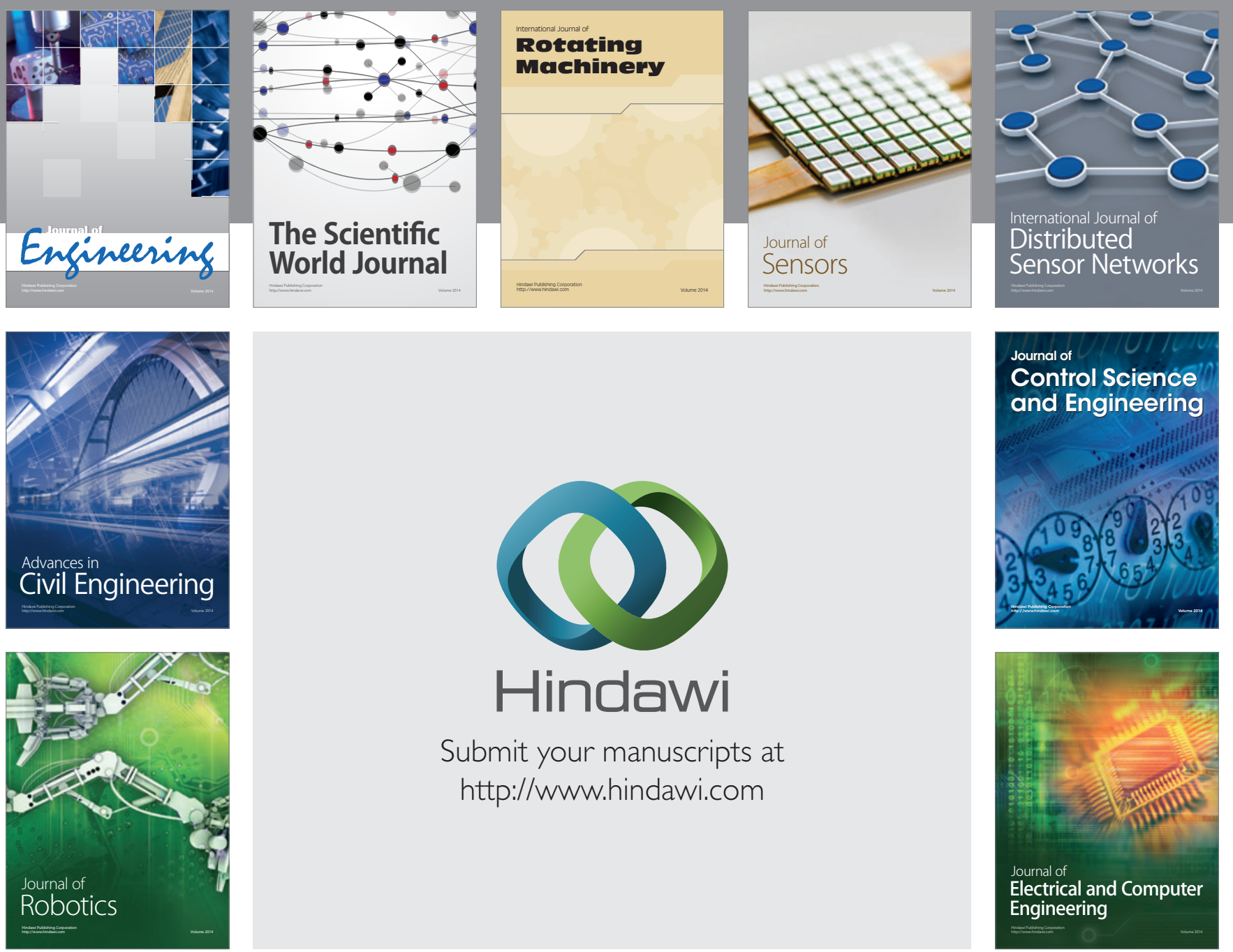

Submit your manuscripts at

http://www.hindawi.com
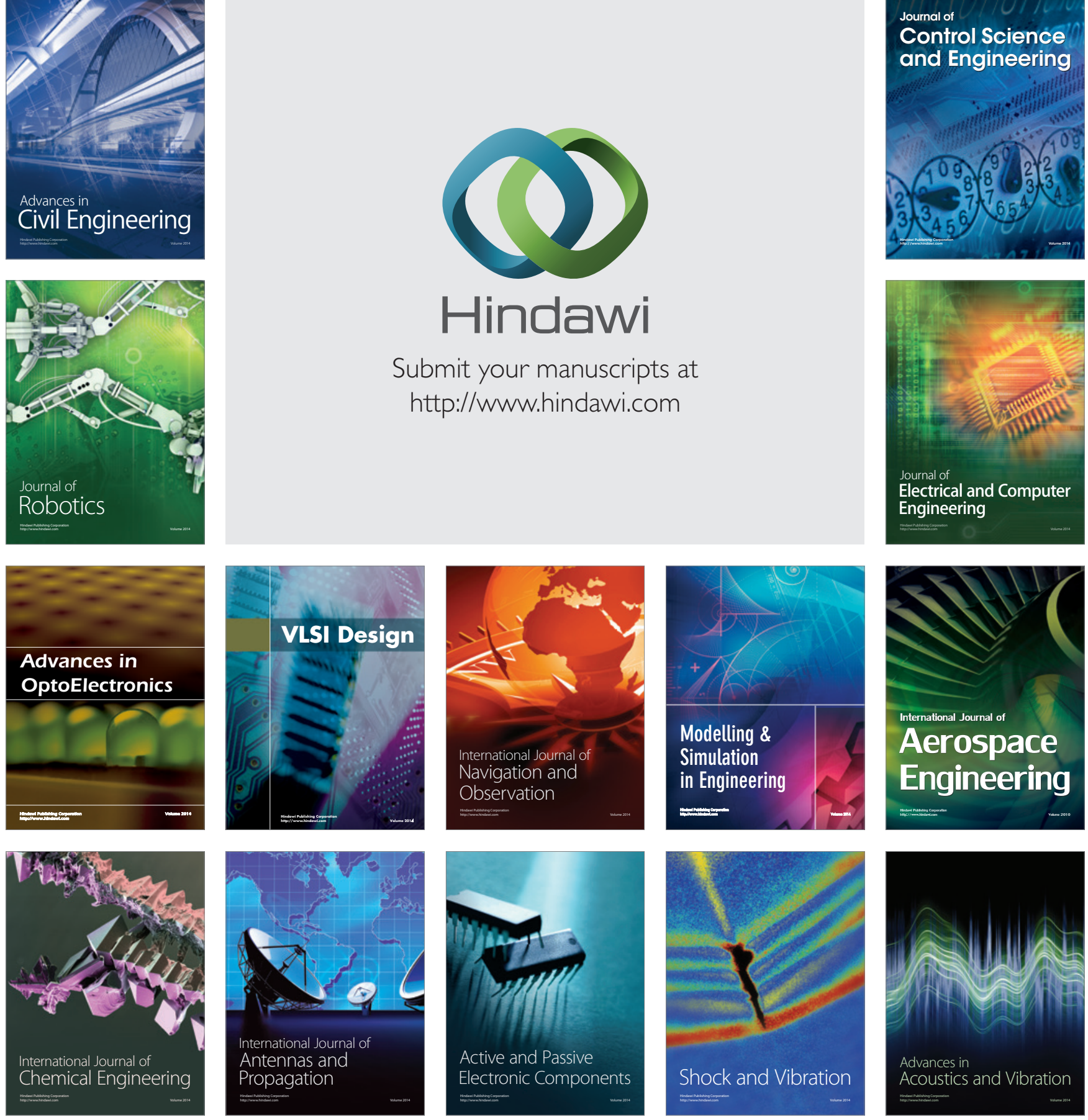